\title{
Development of high strength bamboo paper using parenchyma cells
}

\author{
S. Suzuki ${ }^{1}$, K. Okubo ${ }^{2} \&$ T. Fujii ${ }^{2}$ \\ ${ }^{1}$ Graduate student of Doshisha University, Japan \\ ${ }^{2}$ Department of Mechanical Engineering, Doshisha University, Japan
}

\begin{abstract}
The purpose of this study is to develop a high strength paper fabricated with bamboo single fibers. The fibers were extracted from Moso bamboo trees between two months to four years old. The experiments in this study showed the differences of mechanical properties and dimensions of single fibers according to the age of the bamboo. The mechanical properties of the paper fabricated with the bamboo single fibers were also measured. To increase the adhesive area of bamboo fibers in the paper, parenchyma cells were additionally supplied into the material of the paper. The effect of the weight content of the parenchyma cell on the tensile strength was discussed to determine the appropriate ratio of enhancements.

The superior mechanical properties of elastic modulus and the tensile strength of single fibers were obtained when relatively young bamboo was selected as the material. Two year old bamboo has proper parenchyma cells for the heat-sealing between fibers to improve the strength of paper fabricated with bamboo fibers. The tensile strength of the paper was improved when the bamboo paper contained $10 \%$ parenchyma cells by weight.
\end{abstract}

Keywords: bamboo, paper, parenchyma cell, single fiber, adhesion, age of bamboo, cellulose.

\section{Introduction}

World paper consumption was about 300 million tons in 1996/1997 and is expected to rise above 400 million tons by the year 2010 [1]. In view of the shortage of conventional raw materials for pulping and increasing demand for paper products worldwide, bamboo, which grows quickly, has attracted public 
interest as an alternative resource for industrial paper [2]. The bamboo fibers are also focused on because of their high specific strength [3-6].

Some studies regarded bamboo as a natural resource and developed types of bamboo paper made of the extracted natural bamboo [7,8]. However, the bamboo paper has insufficient mechanical properties for structural uses or to be used for applications in which high strength is expected. Bamboo paper should also be available in industrial products by the improvement of the mechanical properties of the paper [8]. The strength of the paper depends on the strength of the constructing single fibers and the adhesions between the fibers [9-13]. To improve the mechanical properties of the paper using the single bamboo fibers, the age of the bamboo should be considered in its application, because the basic structure of bamboo fiber is transformed according to the age of bamboo. The adhesion between single fibers should be also influenced by the components of the single fiber.

The purpose of this study is to develop a high strength paper fabricated with bamboo single fibers. The fibers were extracted from Moso bamboo trees between two months and four years old. The experiments in this study, at first, showed the differences in the mechanical properties and dimensions of single fibers according to the age of bamboo. Then, the mechanical properties of the paper fabricated with the bamboo single fibers were also measured. To increase the adhesive area of bamboo fibers in the paper, parenchyma cells were additionally supplied into the matrial of the paper. The effect of the weight content of the parenchyma cells on the tensile strength was discussed to determine the appropriate ratio of enhancements.

\section{Materials}

\subsection{Fabrication of pulp}

The bamboo fibers were extracted from naturally grown Moso bamboo trees in the campus of Doshisha University Japan, in which the age of the bamboo trees was between two months to four years. To extract the bamboo fiber bundles, the piece of bamboo was immersed for 10 hours in a solution of $\mathrm{NaOH}$ with $2 \mathrm{~mol} / \mathrm{l}$ concentration at $90 \mathrm{c}$ '. The fiber bundles were washed and then rubbed in water to remove the parenchyma cells that remained on the surface of bamboo bundle. The bamboo bundles were separated into single fibers in a mixing machine with a $1.8 \mathrm{~L}$ chamber and a rotor driven by a $295 \mathrm{w}$ motor.

\subsection{Parenchyma cell}

The eliminated parenchyma cells were re-collected with a \#120 mesh from the suspension in washing process of the bamboo fiber bundles. The agglomerates were segregated at 105 degree $\mathrm{C}$ for 10 hours (Figure 1).

\subsection{Manufacture of paper}

The wet bamboo sheet was processed by the conventional paper making method using filtrated single bamboo fibers. The wet sheets were pressed under $20 \mathrm{MPa}$ 
at 160 degree $\mathrm{C}$ for 5 minutes in a heat-pressing machine. The bamboo paper was obtained in flat shape by this process.

\section{Experimental method}

\subsection{Optical evaluation of fiber dimensions}

The fiber diameter and length of the single fibers were optically determined under the light microscope (KEYENCE, VH7000) after they were randomly set on slide glass by a pipette and then dried for 12 hours at room temperature.

\subsection{Tensile test of single fiber}

The tensile load was applied to the single bamboo fiber previously glued on a paper fixture (figure 2) with epoxy adhesive to obtain Young's modulus and the ultimate strength of the fiber. The fiber diameter and length of the single fibers were also optically measured under the same light microscope explained in section 3.1. In the test, the crosshead speed was controlled at $1 \mathrm{~mm} / \mathrm{min}$ by a low capacity tensile testing machine (Ez-test500: Max. load=500N, SHIMADZU). The Young's modules were nominally defined as the initial linear slope of the stress-strain curve.

\subsection{Estimation of cellulose content}

It is generally known that bamboo fiber consists of cellulose, hemicellulose and lignin [6,14-16]. The holocellulose is constructed with the cellulose and hemicellulose, which are non-wood materials.

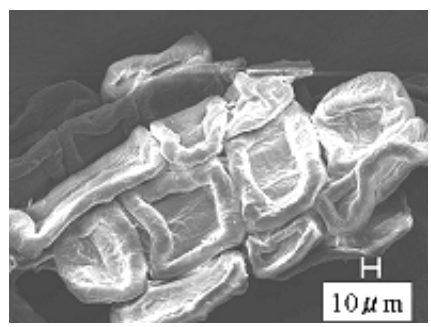

Figure 1: $\quad$ Parenchyma cell.

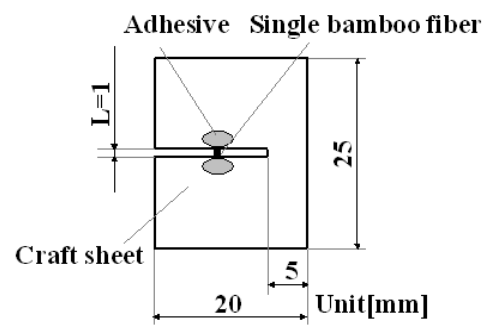

Figure 2: Dimensions of specimen for tensile test. 
In this study, at first, the holocellulose was extracted with by delignification treatment (Wise method), which removes lignin from the bamboo fibers. Secondly, the cellulose was obtained by removing the hemicellulose from the holocellulose, where the material was immersed into a $17.5 \%$ aqueous sodium hydroxide and acetic acid. The wet cellulose was filtrated by a glass filter with a vacuum under $0.06 \mathrm{MPa}$. Then the remaining material was dried at 105 degree $\mathrm{c}$ in an electric oven. The content of the cellulose in the bamboo fiber was estimated with the obtained weight of cellulose by the current method.

\subsection{Tensile test of paper}

The static mechanical properties of the obtained bamboo paper were evaluated with the same tensile test machine for the tests of extracted bamboo fiber, while the crosshead speed was $10 \mathrm{~mm} / \mathrm{min}$ for the paper specimen with dimensions of $10 \times 50 \mathrm{~mm}$. The cross section of the paper was defined with the average thickness measured by the micrometer on the three points of the specimen. The Young's modules were determined from the straight-line part of the stress-strain curve. The fabricated paper was assumed to be isotropic in all tests.

\section{Result and discussion}

\subsection{Mechanical properties of single fibers}

Table 1 shows the diameter, length and aspect ratio of extracted bamboo fibers used in this study. The single bamboo fiber with a small diameter was obtained from young bamboo. The reduction fiber diameter was explained by the shrinkage of the cells in the young bamboo. The high aspect ratio of the single

Table 1: $\quad$ Single fiber geometries.

\begin{tabular}{|c|c|c|c|}
\hline Period of growing & Diameter $[\mu \mathrm{m}]$ & Length $[\mu \mathrm{m}]$ & Aspect ratio \\
\hline 2 months & 12.3 & 2077.6 & 169.4 \\
\hline 4 months & 14.8 & 2267.8 & 154.5 \\
\hline 1 year & 16.4 & 2313.4 & 151.8 \\
\hline 2 years & 16.6 & 2295.3 & 142.5 \\
\hline more 4 years & 18.0 & 2156.9 & 121.9 \\
\hline
\end{tabular}

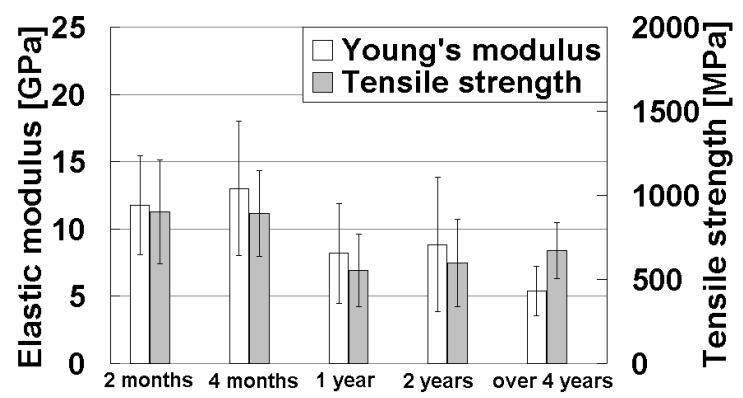

Figure 3: Variation of elastic modulus and tensile strength of single fibers with respect to age. 
fiber was obtained due to the shrinkage of the cells when young Moso bamboo was selected as well as other kinds of plants.

Figure 3 shows the variation of elastic modulus and the tensile strength of single fibers with respect to age. Superior mechanical properties of elastic modulus and tensile strength of single fibers were obtained when relatively young bamboo was selected as the material. Figure 4 shows the tensile strength of the single fiber with respect to the content of included cellulose shown in section 3.3. The high strength of the single bamboo fiber was obtained at a high cellulose content.

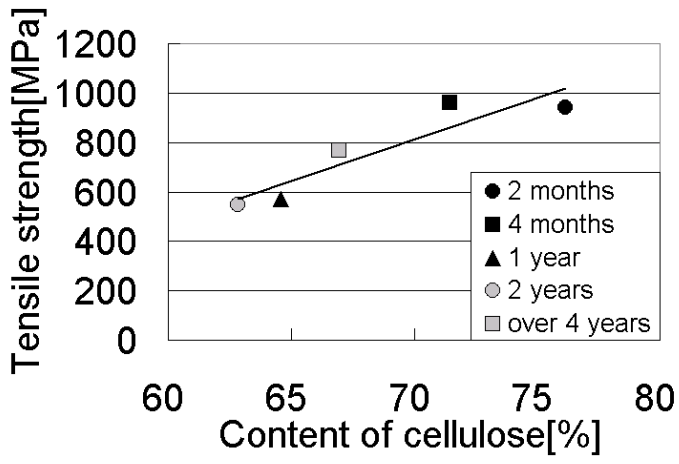

Figure 4: Tensile strength of single fiber with respect to content of included cellulose.

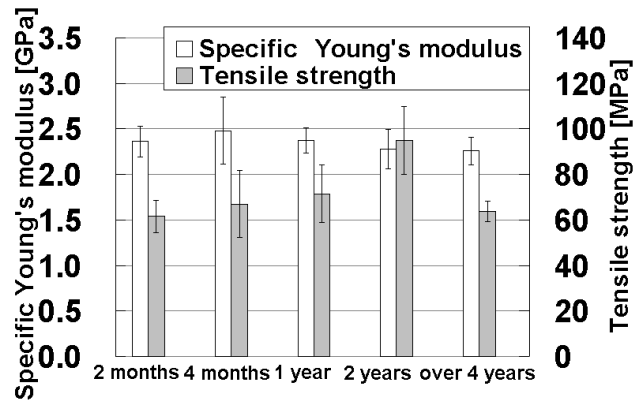

Figure 5: Mechanical properties of the paper with respect to age of the bamboo.

\subsection{Mechanical properties of paper}

Figure 5 shows the variation of specific Young's modulus and tensile strength of the fabricated paper with respect to the age of material. The tensile strength of the paper was remarkably affected with respect to the age while a slight variation of specific Young's modulus of the paper was shown in the test. The tensile strength of the paper showed highest among all specimens when the fibers 
extracted from the two year old bamboo were used as the material of paper. Low tensile strength was defined using the two month old pulp with the maximum fiber strength.

Figure 6 shows the fabricated paper and its fracture surface. The fiber pullouts were observed in the paper fabricated with the fibers extracted from two month old bamboo, while such pullouts were not shown when the fibers were extracted from the two year old bamboo. The pictures show that parenchyma cells were heat-sealed to the fibers at an elevated temperature under the pressing process when the two year old bamboo was selected. It is said that the two year old bamboo has proper parenchyma cells for the heat-sealing between fibers to improve the strength of paper fabricated with bamboo fibers.

(a)

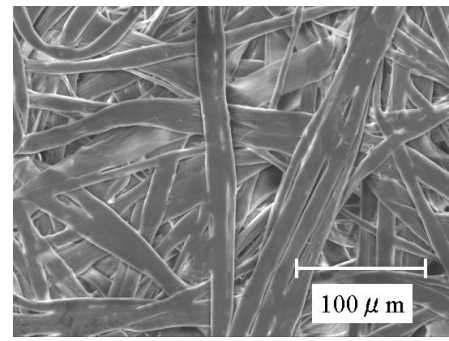

2 months

Surface of paper

(b)

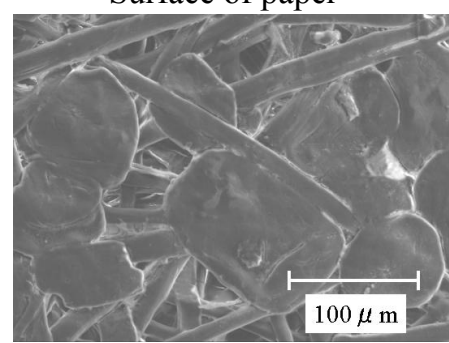

2 years

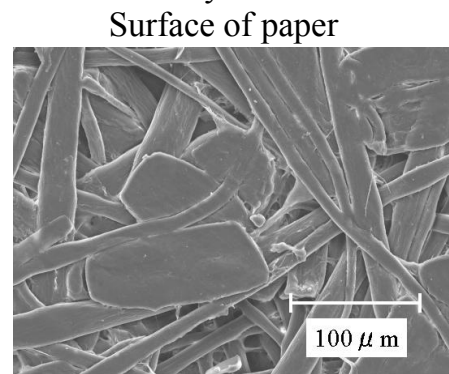

over 4 years

Surface of paper

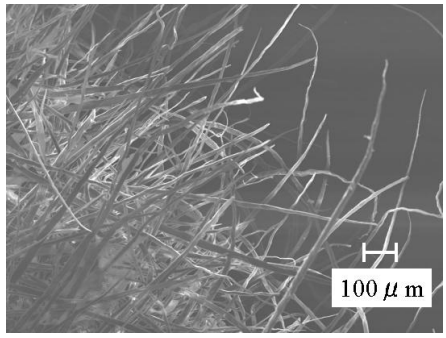

2 months

Fracture surface of the paper

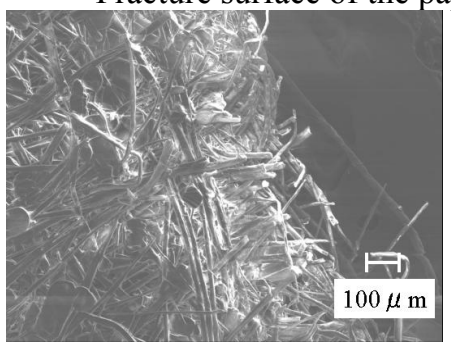

2 years

Fracture surface of the paper

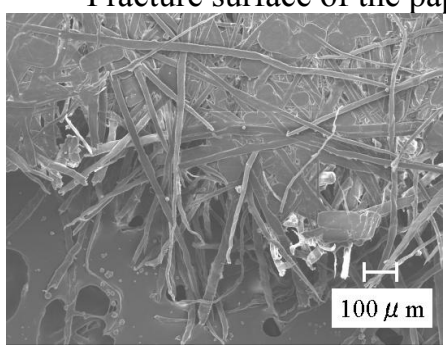

over 4 years

Fracture surface of the paper

Figure 6: Fracture surface of the paper. 


\subsection{Effect of parenchyma cell addition on tensile strength}

To increase the adhesive area of bamboo fibers in the paper, the previously extracted parenchyma cells were supplied into the material of the paper. The wet bamboo paper including the additionally supplied parenchyma cells was processed by the conventional paper making method shown in section 2.1, after the parenchyma cells were stirred into the bamboo fibers by a rotor. In this session, fibers extracted from four month old bamboo were used in which the highest fiber strength was shown in all types of fibers. Five types of samples having different parenchyma cell contents in weight were prepared. The weight content of the parenchyma cells was varied in 5 levels from 0 (as control), 10, $20,30,40$ and $50 \%$.

Figure 7 shows the surface of fabricated papers in this session. A lot of heat-sealed points were observed on the bamboo fibers when the additional parenchyma cells were supplied into the paper. Figure 8 shows the change of tensile strength according to the weight content of the parenchyma cells. The tensile strengths were improved when the bamboo paper had a $10 \%$ content by weight of parenchyma cells. However, the paper with a high content of parenchyma cells (over $10 \%$ by weight) showed lower tensile strength than that without the addition.

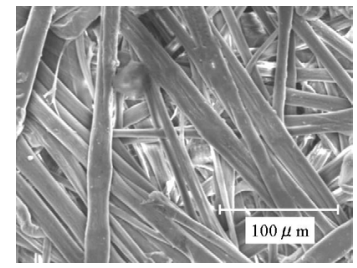

$0 w t \%$

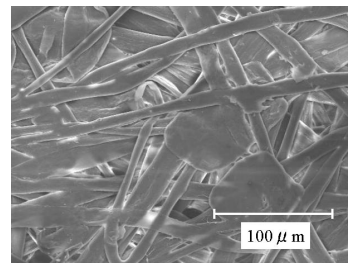

$10 \mathrm{wt} \%$

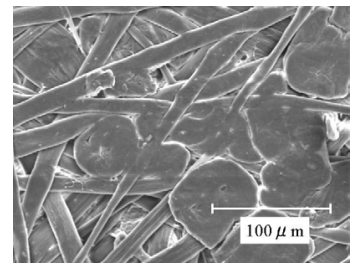

$30 \mathrm{wt} \%$

Figure 7: $\quad$ Surface state of the paper.

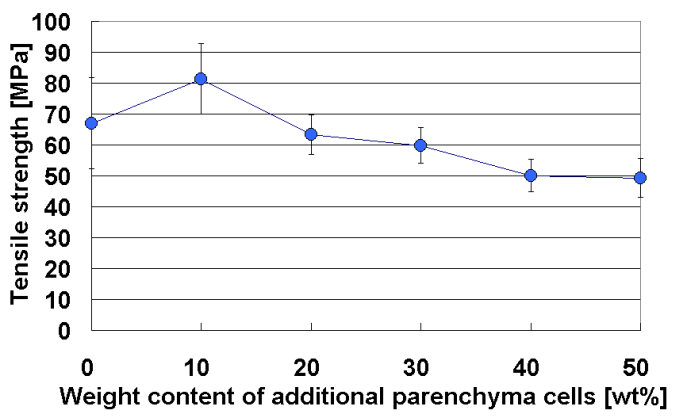

Figure 8: Tensile strength with respect to weight content of parenchyma cell. 
Figure 9 shows the fracture surface of the paper having 10 and $50 \mathrm{wt} \%$ of added parenchyma cells. Few fiber pullouts were observed in the fracture surfaces of both papers. The adhesion between fibers was successively fixed even if a small ratio of additional parenchyma cells was supplied into the paper. These results suggested that the highest paper strength was obtained under the condition of a small ratio of additional parenchyma cells due to the proper improvement of adhesion between the bamboo fibers that form main structure of the paper, while the matrix properties around the fibers were degraded by using more than $10 \%$ additional parenchyma cells, which had a low strength.

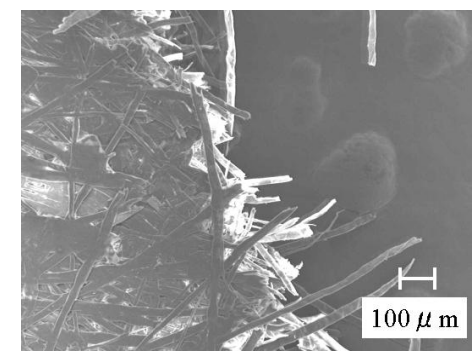

$10 \mathrm{wt} \%$ addition of parenchyma cells

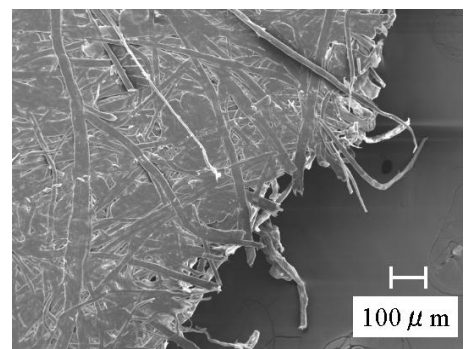

$50 \mathrm{wt} \%$ addition of parenchyma cells

Figure 9: $\quad$ Fracture surface of the paper.

\section{Conclusion}

This study proposed an effective technique to improve the strength of bamboo paper using parenchyma cells. The current study discussed, firstly, the difference in mechanical properties of bamboo fibers according to the age of the bamboo. The mechanical properties of paper fabricated with the bamboo single fibers were also evaluated in consideration with the age of the bamboo.

Some conclusions could be obtained as follows:

1) Superior mechanical properties of elastic modulus and tensile strength of the single fibers were obtained when relatively young bamboo was selected as the material.

2) Two year old bamboo has proper parenchyma cells for heat-sealing between fibers to improve the strength of paper fabricated with bamboo fibers.

3) The tensile strength of the paper was improved when the bamboo paper had a content of $10 \%$ by weight of parenchyma cells.

\section{References}

[1] Hurter, R.W., Ricco, F.A., 1998. Why CEOS don't want to hear about non woods-or should they, TAPPI Proceedings, NA Nonwood Fiber Symposium, Atlanta, GA, USA, pp. 1-11.

[2] C. Ververi, K. Georghiou, N. Christodoulakis, P. Santas, R. Santas, Industrial Crops and Products, 19, pp. 245-254, 2004. 
[3] T. Shito, K. Okubo, T. Fujii. High Performance Structures and Composites, pp. 175-182, 2002.

[4] Y. Yamamoto, K. Okubo, T. Fujii, Proceedings of International Workshop on Green Compo, pp30-34, 2002.

[5] K. Murali Mohan Rao, K. Mohana Rao, Composite Structures, pp.1-8, 2005.

[6] Nobuya Takahashi, Kazuya Okubo And Toru Fujiii, Development of green composites using cellulose-microfibrils extracted from bamboo without polymer adhesive, IWGC-3, pp.111-115 (2005).

[7] Yohei Jin, Kazuya Okubo, Toru Fujii, Improvement of mechanical properties of paper sheet fabricated with beaten bamboo with PVA enhancer, IWGC4 (Fourth International Workshop on Green Composites), pp. 45-50.

[8] Yohei Jin, Kazuya Okubo and Toru Fujii, Effective technique to improve mechanical properties of paper sheet fabricated with bamboo, China-Japan Joint Seminar on Green Composites, pp. G-17-G-18, 2005.

[9] Bai SL, Hu GK. , Eng Fract Mech, 56(1), pp 57-64, 1997.

[10] Teishev A, Maron A., J Appl Polym Sci, 56, pp 959-966, 1995.

[11] Kodokian KA, Kinloch AJ,. J Mater Sci. 7, pp 625-627, 1988.

[12] Yuan LY, Shyu SS, Lai JY., Comp Sci Technol, 1992, 45, pp 9-16.

[13] Kill G, Hunter DH, McIntyre NS., J Polym Sci: Part A polym Chm, 34, pp 2299-2310, 1996.

[14] M. Sarwar Jahan, D.A. Nasima Chowdhury, M. Khalidul Islam, Characterization and evaluation of golpata fronds as pulping raw materials, Bioresource Technology, 97, pp.401-406, 2006.

[15] Seema jain Rakesh kumar, U.C. Jindal, Mechanical behavior of bamboo and bamboo composite, Journal of materials science, 27, pp. 4598-4604, 1992.

[16] D. Fengel, X. Shao, A chemical and ultrastructural study of the bamboo species Phyllostachys makinoi Hay., Wood Science and Technology, 18, pp.103-112, 1984. 